\title{
Learning Vocabulary through Collocating on Quizlet
}

\author{
Mehdi Solhi Andarab \\ School of Education, Istanbul Medipol University, Turkey
}

Copyright $\bigcirc 2019$ by authors, all rights reserved. Authors agree that this article remains permanently open access under the terms of the Creative Commons Attribution License 4.0 International License

\begin{abstract}
The difficulty in learning vocabulary is a problem that lies in not anchoring the new items to relevant established entities in cognitive structure. Different categories of associations have been reported to aid facilitating vocabulary acquisition. Collocating vocabulary items is a type of association that is considered to be more efficient in retrieval. The present study sought to investigate whether collocating the lexical items on Quizlet can facilitate acquisition of the vocabulary items, and whether it is likely to be more effective than learning decontextualized individual words. In so doing, 70 upper-intermediate English as a foreign language (EFL) learners with homogenous knowledge of vocabulary were conveniently assigned into two groups: the learners in the first group were assigned a list of vocabulary items with their synonyms in English, while the learners in the other group were assigned the identical vocabulary items with their frequent collocations written in complete sentences. The targeted collocations were verb-nouns, propositional verbs, and noun-nouns. The assignment continued for two months. At the end, an independent sample t-test applied on the scores achieved from a posttest indicated a significant difference in scores of the control group and that of the experimental group. This study sheds light to the significance of contextualizing a lexical item with collocations through which acquisition of vocabulary item is enhanced.
\end{abstract}

Keywords Collocation, Quizlet, Vocabulary

\section{Introduction}

Almost all English language teachers are somewhat familiar with the complaints of the students saying that they possess many individual words, but they still have trouble expressing complex ideas simply and impeccably. Put simply, they are familiar with the words, but not with the sequences of the words, that is, collocations. In the online dictionary of Oxford, the word collocation has been defined as "the habitual juxtaposition of a particular word with another word or words with a frequency greater than chance". Robins similarly (2000, p.64) defines collocation as "the habitual association of a word in a language with other particular words in sentences". Formulaic language and collocation in particular possess an important place in vocabulary acquisition to have fluent and idiomatic language use. Durrant and Schmitt (2010) point out to the predictive characteristic of collocating words, stating that when we locate "one part of a collocating pair, the chances of finding the other increase" (p. 1). Szudarski (2017) similarly underlines the pivotal role of the collocations in successful communication and language use. Nation (2000, as cited in Shaoqun Wu, Witten \& Franken, 2010) summarizes the importance of collocations, saying that "language knowledge is collocational knowledge; collocational knowledge is important for developing both fluency and accuracy; [and] knowing a word involves knowing its set of its collocates" (p. 2). Hill (1999) conceptualizes the term collocational competence and insists that acquisition of lexis cannot be attained by only knowing the meaning of individual words, rather by their collocational span.

However, despite the facilitating contribution attached to the idea of collocation, building up a collocational competence has always been a big challenge for the learners. Two decades ago, Hill (1999) asserted that English language students with great ideas normally fail to attain higher grades in writing because they are not familiar with the most frequently-occurred collocations in English. In fact, collocational errors are reported to be the most frequently made mistakes by English language learners (James, 1998). A group of scholars contribute this difficulty and slow process in developing collocations to cross-linguistic inconstancy of collocations in different languages and an insufficient emphasis on the traditional focus on teaching individual words rather than collocations (Boers, Lindstromberg, and Eyckmans, 2014; Henriksen, 2013). Pavičić Takač and Miščin (2013) similarly attribute the failure to the interference with their mother tongue.

Coursebooks are also criticized for not allocating sufficient place to collocations. Tsai (2015), for instance, states that collocations are marginalized in the coursebooks, or often presented out of context (Nurmukhamedov, 2016), 
which is less likely to lead to learning because "collocations occur in discourse; thus L2 writers should be familiar with the contextual use of collocations" (p. 2). Echoing the importance of collocations, Farghal and Obidedate (2009) in their study indicated that the collocative knowledge of the students is deficient, and they attributed this lack of knowledge to the fact that teaching collocations is ignored in the classroom. Along with the other scholars, Shaoqun Wu, Witten \& Franken (2010) criticize the traditional focus of curriculum, in which too much overreliance on grammar because of the ease of its teaching and testing has deprived the students of the collocational competence. They also add that identifying a set of beneficial collocations is a challenging task on the part of the teachers, and they are insufficiently trained to teach collocations. Kilickaya and Krajka (2010) similarly point out that despite the availability of a large number of practical books on how to benefit from computer resources in the process of language teaching, language teachers still rely on traditional ways to teach vocabulary. They recommend language teachers to enrich their teaching practice with a variety of resources and tools.

\subsection{Collocation and Long-term Memory}

Transferring and internalizing the lexical information to the long-term memory has always been the concern of the scholars (Ellis, 2001; Krashen and Terrell, 2000; Schmitt, 2000). Ellis (2001) puts forward a model of learning collocations in the process of first language acquisition. He believes that collocations are the products of a psychological process names as 'chunking' in which when two or more words frequently co-occur, they are recoded as chunks and eventually recognized as a single entity. This recursive process enables someone to combine and expand the collocations into longer sequences, and subsequently to codify huge quantity of information in memory. Ellis (2001) believes that when the words occur and are learned together, they become associative, and we are more likely to recall the whole chunks when any piece of the collocation is encountered. In line with Ellis's model, in a study, Boers, Dang, and Strong (2017) indicated that studying collocations as holistic units without attending to their discrete components was reported to be the most productive way of promoting and recalling collocation knowledge. Krashen and Terrell (2000) similarly argue that 'memorized' or 'drilled' vocabulary does not stick in mind. In other words, rote learning or drills do not bring about long-term retention of vocabulary. Hence, meaningful learning of lexical items results in acquisition of vocabularies with permanent memory retention. They argue in favor of contextualizing the vocabulary items to increase the process of retention into the longer-term memory. Carter and McCarthy (1988) similarly advocate the idea of teaching vocabularies in context. These scholars believe that to enrich the context of the vocabulary and to increase the possibility of detainment, teachers are recommended to collocate the lexical items in a sentence or sentences. In a study, years ago, Nattinger (1988) also supported the idea of contextualizing the lexical items. She indicated that the longer and more complex the sentences are, more likely they are to be recalled. In fact, research indicates the significance of contextualizing vocabulary items to enhance the retention of them into the long-term memory.

On the other hand, a group of scholars argue in favor of explicit teaching of collocations. Durrant and Schmitt (2010), for instance, believe that unlike idiomatic expressions and other longer strings, collocations are more likely to be subject to explicit processes of acquisition than other sequences. Bahns and Eldaw (1993) similarly advocate the idea of teaching collocations explicitly in the classroom. Learning collocation is a cumulative process encompassing a great deal beyond rote memorization. Collocation learning cannot be achieved unless they are "deliberately selected, prioritized, and incorporated into language learning material" (Swan, 1996, as cited in Shaoqun Wu, Witten \& Franken, 2010, p. 3).

\subsection{Online Applications and Collocations}

The recent improvements in technology and their integration in vocabulary learning have dramatically facilitated the process of learning languages. The integration of technology to enhance the vocabulary span of the learners has been emphasized and investigated in research (Busch, 2003; McGlinn \& Parrish, 2002; Tozcu \& Coady, 2004). In one part of their study, Tozcu and Coady (2004) investigated the effect of direct vocabulary learning with the help of computer assisted language learning (CALL) on vocabulary knowledge. The results indicated that the students who used Tutorial CALL to learn the most frequent vocabulary items significantly outperformed the control group whose instruction was based on traditional vocabulary training, as they were able to learn a larger number of words in comparison to their counterparts. Nurmukhamedov (2016) explored the effect of three collocation tools (two online and one paper) on the accurate correction of collocative mistakes by second language writers in an attempt to find out whether second language writers benefit from collocation tools. Results indicated that there was a statistically significant difference among the tools: online collocation tools (Longman Dictionary of Contemporary English and www.wordandphrase.info) contributed more than a book collocation dictionary (Macmillan Collocation Dictionary) to accurate collocation production in second language writers' essays. Dziemianko's (2010) study also indicated that the online dictionary group outperformed significantly in receptive and productive collocation tasks their paper dictionary counterparts. In a recent study, Khodary (2017) investigated the effectiveness of using the Vocabulary 
Self-Collection Strategy Plus (VSSPlus) on improving university students' vocabulary learning. The results revealed a significant between the students who received training on the VSSPlus and their counterparts in the control group. The experimental group also outperformed the control group on the following vocabulary achievement test with the help of training on the VSSPlus.

\subsection{Quizlet and Learning Vocabulary}

Amongst the varied and prevalent applications that are utilized in teaching vocabulary, Quizlet is an excellent teacher-/student-friendly online vocabulary management system with an application and a website, catering for users seven powerful vocabulary learning tools for the creation of different vocabulary activities. With its different options to review the learned vocabulary items, Quizlet helps students track their vocabulary learning. Exceeding 150 million study sets to choose from, Quizlet is estimated to be the world's largest student and teacher online learning community, and it is, undoubtedly, one of the most popular language learning technology tools on the internet. In order to create your own Quizlet, one needs to prepare a two-column list of words or phrases. This set of vocabulary can be a word and its definition, translation, synonym, antonyms, etc. After creating a two-column study set and importing it to the website, the site automatically and immediately creates the following seven game mode activities:

- $\quad$ Flashcards - This mode lets you study Quizlet sets as flashcards. One can play this activity to review the study set and listen to the pronunciation of the word or the phrase.

- Learn - Learn mode assesses how well you know the definitions of the words and keeps track of what you miss. To move forward, one must type the answer and click on the Answer button or press Enter to see if the answer was correct or incorrect. So, this mode lets you focus on missed or unknown terms later in the study session.

- $\quad$ Spell - Spell mode lets you type what you hear to improve your spelling in this audio-powered study mode. This mode works well for studying a new language or practicing your spelling and pronunciation. There are 18 languages, enabling you to use Spell with a wide variety of sets.

- $\quad$ Test - Test randomly generates tests based on your flashcard set. Therefore, this mode is excellent to practice before a quiz or exam to assure you have thoroughly learned the terms. You can choose different combinations of question types depending on what works best for you.

- Match - This mode lets you race against the clock and match your terms and definitions as quickly as possible. You can use Match mode to compete with your classmates for the top score.
- Gravity - This mode lets you type your answers as the asteroids fall. As you pass levels, the force of gravity increases, and the asteroids start to fall faster for added challenge.

- $\quad$ Live - This mode lets the students work together and enhance communication to find the term that matches the definition. Students stay focused and communicate to win. Everyone on the team must contribute since none of them has all the answers.

\section{Materials and Methods}

Shaoqun Wu, Witten \& Franken, (2010) maintain that despite the increased integration of computer assisted language learning into language learning which has given birth to a new dimension and dynamic, little research has been conducted on computer assisted collocation acquisition. They add that the linking of technology and computer to learning vocabulary has been restricted to only mechanical drill exercises in which the vocabulary items are pulled out of their original context, and little attention is paid to their use in real language. Apparently, with its well-equipped modes, the idea of integrating technology and collocating vocabulary items can be thoroughly accomplished through Quizlet. In so doing, in this study, the acquisition of vocabulary through collocating on Quizlet was taken into scrutiny to find out whether collocating the vocabulary items with their frequently occurred collocations in a context is likely to lead to better learning of them. Hence, the following research question was formulated:

Q1: Does collocating the lexical items on Quizlet account for the acquisition of the vocabulary items?

\subsection{The Participants}

The participants consisted of 70 (42 female and 28 male) upper-intermediate EFL learners studying at the preparatory school of a private university in Turkey with homogenous knowledge of vocabulary. Their knowledge of vocabulary was assessed using a standardized placement and a proficiency exam of the university respectively. They were aged 18-24 years old, and conveniently assigned into two groups: 35 in the control group and 35 in the experimental group. This study was conducted in the first semester of the academic year.

\subsection{The Procedure}

The learners in the first group (control group) were assigned a list of vocabulary items with their synonyms in English on Quizlet, while the learners in the other group (experimental group) were assigned the identical vocabulary items with their frequent collocations written in at some sentences. The vocabulary items selected for the assignments of the students in the both groups were the 
ones listed at the end of the chapters of the reading coursebooks being used in the reading courses at the preparatory school of the university. Each week, 30 to 40 difficult vocabulary items chosen from the readings were set on Quizlet, and the students were expected to complete the assignments in four days. The participants were supposed to do only Learn and Test modes of the activities on Quizlet. At the end of the deadline, the instructor controlled the assignments online to ensure that they finished their tasks. The frequently-occurred collocations assigned for the experimental group were in complete sentences, considering the proficiency level of the students. The majority of the collocations were verb-nouns (e.g., pose a problem and do the laundry), propositional collocations (e.g., burst into tears and swell with pride), and noun-nouns (e.g., a surge of anger and pang of nostalgia). The assignment continued for two months.

\subsection{The Instruments}

A pretest and a posttest each consisting of 60 fill-in-the gap vocabulary questions were administered to the participants. The two versions of the tests were equivalent in terms of difficulty and content. In order to ensure that there is not a significant difference between the pretest score of the control group and that of the experimental group first the pretest was administered. At the end, the posttest was given to assess whether there was any significant difference between the mean scores of the control and the experimental groups.

\section{Result}

With this purpose, an independent t-test analysis of variance between the two groups was conducted. The results obtained from the $t$-test run (Table 1) indicated that there was not a significant difference between the scores of the participants in the control $(\mathrm{M}=57.25, \mathrm{SD}=18.05)$ and the experimental $(\mathrm{M}=50.22, \mathrm{SD}=15.39)$ groups in terms of their vocabulary knowledge $t(68)=1.752, p=.084$. Then the treatment started.

After conducting the treatment, at the end of the term, the other equivalent test (post-test) consisting of 60 fill-in-the gap sentences was administered to the students to assess the effect of treatment on their vocabulary learning. They received twenty sentences without verbs of the target verb-noun collocations, twenty without propositions of the target propositional collocations, and twenty without nouns of the target noun-noun collocations. An independent samples t-test (Table 2) applied on the scores achieved from a posttest indicated a significant difference in scores of the control $(\mathrm{M}=66.77, \mathrm{SD}=11.08)$ and that of the experimental $(M=80.71, S D=10.51)$ groups; $t(68)=-5.40$, $p<.000$.

Table 1. Independent samples t-test for pretest

\begin{tabular}{|c|c|c|c|c|c|c|}
\hline & $\mathrm{F}$ & $\mathrm{Sig}$ & $\mathrm{t}$ & $\mathrm{df}$ & Sig.(2-tailed) & Mean D \\
\hline Equal variances assumed & 0.348 & 0.557 & 1.75 & 68 & 0.084 & 7.02 \\
\hline Equal variances not assumed & & & 1.75 & 66.3 & 0.084 & 7.02 \\
\hline
\end{tabular}

Table 2. Independent samples t-test for posttest

\begin{tabular}{|c|c|c|c|c|c|}
\hline & F & Sig & t & df & $\begin{array}{c}\text { Mean } \\
\text { Difference }\end{array}$ \\
\hline Equal variances assumed & 0.018 & 0.894 & -5.4 & 68 & -13.94 \\
\hline Equal variances not assumed & & & -5.4 & 67.8 & 0 \\
\hline
\end{tabular}




\section{Conclusions}

In this study, the acquisition of vocabulary through collocating on Quizlet was taken into scrutiny to investigate whether collocating vocabulary items with their frequently occurred collocations in a context is likely to lead to their learning. In so doing, as aforementioned, the participants in the control group were assigned a list of vocabulary items with their synonyms in English, while the ones in the experimental group were assigned the identical vocabulary items but with their frequent collocations written in complete sentences on Quizlet. The verb-nouns, propositional verbs, and noun-nouns were the targeted collocations in this study. In fact, results indicated a significant difference in scores of the control group and that of the experimental group in the pretest. Although the mean score of the control was slightly higher $(M=57)$ than that of the experimental group ( $M=50)$, the difference was not statistically significant. However, after treatment, as the results indicated, the mean score of the experimental group was significantly bigger than that of the control group. The findings of this study indicate that the contextualization of the vocabulary items with the help of technology while learning vocabulary can enhance the process of learning. The results underline the beneficial role of Quizlet in vocabulary learning, and shed light to the significance of contextualizing a lexical item in a collocation using Quizlet through which learning of vocabulary item is enhanced. As the results advocate, Quizlet needs to be implemented by language instructors who target to help the students build up their vocabulary knowledge. The vocabulary context can be given in one sentence only, but the teacher can also add a couple of sentences in which the word appears. On the basis of the cumulative effect of the sentences, as aforementioned, better learning of the vocabulary items is more likely to be achieved.

In addition, familiarizing the students with the importance of collocations in accuracy and fluency is a factor that needs to be taken into consideration. Shaoqun Wu, Witten and Franken (2010) points to the unfamiliarity of the students with collocations and their failure in noticing collocations and even in understanding their existence and importance in language learning. Arguing in favor of enhancing collocation awareness amongst students, Jiang's (2009) study indicated that in response to the question of whether they paid attention to collocation in the process of learning English before, over half of the students said that they had not paid much attention to collocation before in their educational life. In addition, answering to the question of whether they were told about the importance of collocation in the process of learning English before, two thirds of the them said that they had not been told about the significance of collocation in the process of learning English, and finally in response to the question of whether they already know that collocation dictionaries are useful tools in learning English, almost 90 percent of the students declared that they did not know there were collocation dictionaries at all. Lew's (2004) findings similarly indicated that in response to his questionnaire, about 25 percent of the students declared that they never looked up collocations and about 44 percent stated that they seldom did. Apparently, unawareness about the important role of colocations in accuracy and fluency, learners do not look up collocations in their dictionaries. Kilickaya and Krajka (2010) indicated that not only the students but also the language teachers need to be trained as they are unaware of the opportunities that technology offers. In line with the literature review, Quizlet is also recommended to be individually and collaboratively used by language learners to expand their vocabulary range by being exposed to collocations. In addition, there must be some training programs for the language instructors to familiarize them with the online tools in general and Quizlet in particular.

\section{REFERENCES}

[1] Bahns, J., \& Eldaw, M. (1993). Should we teach EFL students collocations? System, 21(1), 101-114.

[2] Boers, F., Dang, T. C., \& Strong, B. (2017). Comparing the effectiveness of phrase-focused exercises. A partial replication of Boers, Demecheleer, Coxhead and Webb (2014). Language Teaching Research, 21(3), 362-380.

[3] Boers, F., Eyckmans, J., \& Lindstromberg, S. (2014). The effect of a discrimination task on L2 learners' recall of collocations and compounds. International Journal of Applied Linguistics, 24(3), 357-369.

[4] Busch, H. J. (2003). Computer based readers for intermediate foreign-language students. Educational Media International, 40 (3/4), 277-185.

[5] Carter, R., \& McCarthy, M. (1988). Vocabulary and language teaching. London: Longman.

[6] Durrant, P., \& Schmitt, N. (2010). Adult learners' retention of collocations from exposure. Second Language Research, 26(2). 163-188.

[7] Dziemianko, A. (2010). Paper or electronic? The role of dictionary form in language reception, production and the retention of meaning and collocations. International Journal of Lexicography, 23, 257-273.

[8] Ellis, N. C. (2001) Memory for language. In P. Robinson (Eds.), Cognition and second language instruction (pp. 33-68). Cambridge: Cambridge University.

[9] Farghal, M., \& Obidedat, H. (2009). Collocations: A neglected variable in EFL. IRAL, 33(4), 315-331.

[10] Henriksen, B. (2013). Research on L2 learners' collocational competence and development: A progress report. In C. Bardel, C. Lindqvist \& B. Laufer (Eds.), L2 vocabulary acquisition, knowledge and use: New 
perspectives on assessment and corpus analysis (pp. 29-56).

Research, 19, 723-740.

Amsterdam, Netherlands: Eurosla.

[11] Hill, J. (1999). Collocational competence. ETP 11.

[12] Jiang, J. (2009). Designing pedagogic materials to improve awareness and productive use of L2 collocations. In Barfield. A. and H. Gyllstad (Eds.), Researching collocations in another language: multiple interpretations (pp. 99-113). New York: Palgrave Macmillan.

[13] Khodary, M. N. (2017). Using the vocabulary self-collection strategy plus to develop university EFL students' vocabulary learning. English Language Teaching, 10(8), 135-146.

[14] Kilickaya, F., \& Krajka, J. (2010). Teacher's technology use in vocabulary teaching. Academic Exchange Quarterly, 14, 81-86.

[15] Krashen, S. D., \& Terrell, T. D. (2000). The natural approach: Language acquisition in the classroom. (2nd ed.) England: Pearson Education.

[16] Laufer, B (2011). The contribution of dictionary use to the production and retention of collocations in a second language. International Journal of Lexicography, 24(1), 29-49.

[17] Lew, R. (2004). Which dictionary for whom? Receptive use of bilingual monolingual and semi-bilingual dictionaries by polish learners of English. Poznan: Motivex.

[18] McGlinn, J., \& Parrish, A. (2002). Accelerating ESL students' reading progress with accelerated reader. Reading Horizons, 42(3), 175-189.

[19] Nattinger, J. (1988). Some current trends in vocabulary teaching. In R. Carter, \& M. McCarthy (Eds.), Vocabulary and language teaching (pp. 62-82). New York: Longman.

[20] Nurmukhamedov, U. (2016). The contribution of collocation tools to collocation correction in second language writing. International Journal of Lexicography, 4(8), 1-29.

[21] Pavičić Takač, V., \& Miščin, E. (2013). Exploring the collocational competence of non-native users of medical English, JAHR, 4(7), 235-256.

[22] Robins, R. H. (2000). General Linguistics. Beijing: Foreign Language Teaching and Research Press.

[23] Schmitt, N. (2000). Vocabulary in language teaching. Cambridge: Cambridge University Press.

[24] Shaoqun Wu, S., Witten, I. H., \& Franken, M. (2010). Supporting collocation learning with a digital library. Computer Assisted Language Learning, 23(1), 87-110.

[25] Sinclair, J. (1991) Corpus, concordance, collocation. Oxford: Oxford University Press.

[26] Szudarski, P. (2017). Learning and teaching L2 collocations: insights from research. TESL Canada Journal, 34(3), 205-216.

[27] Tozcu, A., \& J. Coady. (2004). Successful Learning of Frequent Vocabulary through CALL also Benefits Reading Comprehension and Speed. Computer Assisted Language Learning, 17(5), 473-495.

[28] Tsai, K. (2015). Profiling the Collocation Use in ELT Textbooks and Learner Writing. Language Teaching 